\title{
NOVEL HETEROCYCLES FROM CREATININE
}

\author{
Aboul-Fetouh E. Mourad , Alaa A. Hassan, Nasr K. Mohamed, \\ Ashraf A. Aly and Bahaa A. Ali \\ Chemistry Department. Faculty of Science. El-Minia University El-Minia. A.R. Egypt
}

\begin{abstract}
Creatinine 1 interacts with some $\pi$-deficient compounds such as tetracyanoethylene. 2.3-
dichloro-5.6-dicyano-1.4-benzoquinone. 2.3.5.6-tetrachloro-1.4-benzoquinone. 2.3-dichloro-1.4naphthoquinone and 2.3-dicyano-1.4-naphthoquinone to give imidazolidinone. imidazolinyl-azomethine. furobisimidazolidine. naphthoimidazoimidazolidine and benzobisimidazoimidazo-lidines derivatives.
\end{abstract}

\section{Introduction}

I-Methyl-2-amino-1.5-dihydroimidazol-4-one (creatinine) belongs to a class of compounds called glycocyamidines. Dry condensation of creatinine with aldehydes under focused microwave irradiation afforded $Z$-arylidene creatinines'. Aminomethyłation of creatinine and its 5 -arylidene derivative with paraformaldehyde. aliphatic primary amines and piperidines gave imidazotriazines ${ }^{2}$ and stereoisomeric piperidinomethyl derivatives. It has been reported that. creatinine reacted with bi(methylthio)methylenemalononitrile. amino acids (alanine. threonine) and glucose to afford bridgehead nitrogen compounds ${ }^{4}$ as well as heterocyclic amines ${ }^{5}$. Furtherm:ore. there are some studies on the structure of the main colouring matter formed in the Jaffe reaction $^{6 . "}$ and oxidation of creatinines ${ }^{8}$.Quantitative estimation of creatinine in biological fluids is of great physiological importance ${ }^{9-12}$. Creatinine is a final product of $\mathrm{c}$ reatine metabolism in physiological systems ${ }^{9}$. also displays also biological activities such as antiparasitic $^{1 ;}$ agents and antimicrobial activities ${ }^{14}$.

Motivated by these facts and pursuing our research in the field of synthesis of heterocyclic as well as fused heterocyclic compounds via reaction of electron-poor multiple bonded compounds with electron-donor

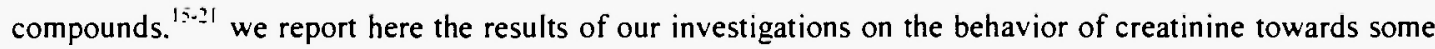
$\pi$-deficient compounds to gain further insight into the chemistry of creatinine (Figure 1).

\footnotetext{
'To whom correspondence should be addressed
} 
<smiles>C=C=C</smiles><smiles>N#CC(C#N)=C(C#N)C#N</smiles>

TCNE<smiles>[X]C1=C([X])C(=O)C([Y])=C([X])C1=O</smiles>

$$
\begin{aligned}
& X=C N . Y=C I . D D Q \\
& X=Y=C l, \text { CHL }-p
\end{aligned}
$$<smiles>[X]C1=C([X])C(=O)c2ccccc2C1=O</smiles>

$X=C N$. DCNQ $X=\mathrm{Cl}, \mathrm{DCHNQ}$

Figure 1

\section{Results and Discussion}

Dimethylformamide solutions of tetracyanoethỵlene (TCNE) and creatinine (1) were kept with stirring at room temperature for 96 hours with admission of air. Chromatographic separation of the residue gave numerous zones. from which products 3- 5 and 7 could be isolated (Scheme 1).

Structural assignments of compounds 3-5 and 7 are based on spectral data and combustion analyses. For 1methỵlimidazolidin-4-only-2-iminomalononitrle (3) the gross formula $\mathrm{C}_{7} \mathrm{H}_{5} \mathrm{~N}_{5} \mathrm{O}$ was confirmed by the mass spectrum. which exhibited a molecular ion at $\mathrm{m} / \mathrm{z} 175$ (100\%). The ${ }^{1} \mathrm{H}-\mathrm{N} M \mathrm{R}$ spectrum of 3 displared two signals at $\delta 2.96$ (s. $\left.3 \mathrm{H} . \mathrm{N}-\mathrm{CH}_{3}\right)$ and 3.95 (s. $2 \mathrm{H} . \mathrm{CH}_{2}$ ): ${ }^{13} \mathrm{C}-\mathrm{NMR}$ spectrum showed the characteristic signals of imidazohdine- $\mathrm{CH}_{\Sigma}$ at $\delta 61.4 \mathrm{ppm}$ and 4-imidazolone carbonyl carbon atom at $\delta 168.5 \mathrm{ppm}$. Also the carbon atom of $[\mathrm{C}(\mathrm{CN})=]$ resonates at $\delta 164.6 \mathrm{ppm}$. whereas the cyano groups at $118.2 \mathrm{ppm}$. Moreorer. the structure of 5 -dicranomethy lene-1-methy -imidazolm-4-only-2-iminomalonontrile (4) has been assigned on the basis of elemental analysis supporting the gross formula $\mathrm{C}_{1,4} \mathrm{H}_{3} \mathrm{~N}_{7} \mathrm{O}$. This was also confirmed by the mass spectrum which gave a correct molecular ion at $\mathrm{m} / \mathrm{z} 237(100 \%)$. 'H-NMR and ${ }^{1 .} \mathrm{C}-\mathrm{NMR}$ as well as IR spectra (see experimental).

For the formation of diimidazolylazomethine derivative 5. two routes can be suggested: in the first one. compound 3 interact with another molecule of 1 with elimination of a molecule of malononitrile. In the second route. compound 2 split off a molecule of $\mathrm{HCN}$ to give tricsanovinglation product 6 . which interacts with another molecule of 1 with elimination of a molecule of malononitrile to give 5 . Elucidation of structure 5 based on 'H-NMR speetrum which reveals the presence of a signal of imidazole- $\mathrm{CH}_{2}$ protons at $\delta=3.99$ ppm indicating that this group is not involved in the course of the reaction. The " $\mathrm{C}$-NMR spectrum supports the presence of imidazole- $\mathrm{CH}_{2}$ at $60.5 \mathrm{ppm}$. and azomethine carbon atom at $163 \mathrm{ppm}$ in addition to the cyano 
and carbonyl carbon atoms. The fragmentation pattern of mass spectrum reveals the presence of (creatinineH) at $\mathrm{m} / \mathrm{z} 112$ and the rest of the molecule at $\mathrm{m} / \mathrm{z} 149\left(\mathrm{M}^{-}-112\right)$. The elemental analysis of compound 5 is a further support of its structure.

Structural proof of furo[2.3-b:4.5-d]bis(1-methylimidazolyl-2-iminomalononitrile) 7 rests on the IR spectrum. which clearly indicates the presence of the cyano groups at $2210 \mathrm{~cm}^{-1}$ and the absence of the carbonyl groups. Also. the 'H-NMR spectrum displayed the presence of a singlet at $\delta 2.95 \mathrm{ppm}\left(6 \mathrm{H}\right.$. $2 \mathrm{CH}_{3}$ ): whereas ${ }^{1} \mathrm{C}$-NMR spectrum showed the imidazole-carbon atoms at $\mathrm{C}-2 . \mathrm{C}-4$. and $\mathrm{C}-5$ at 163.5 .143 .2 and

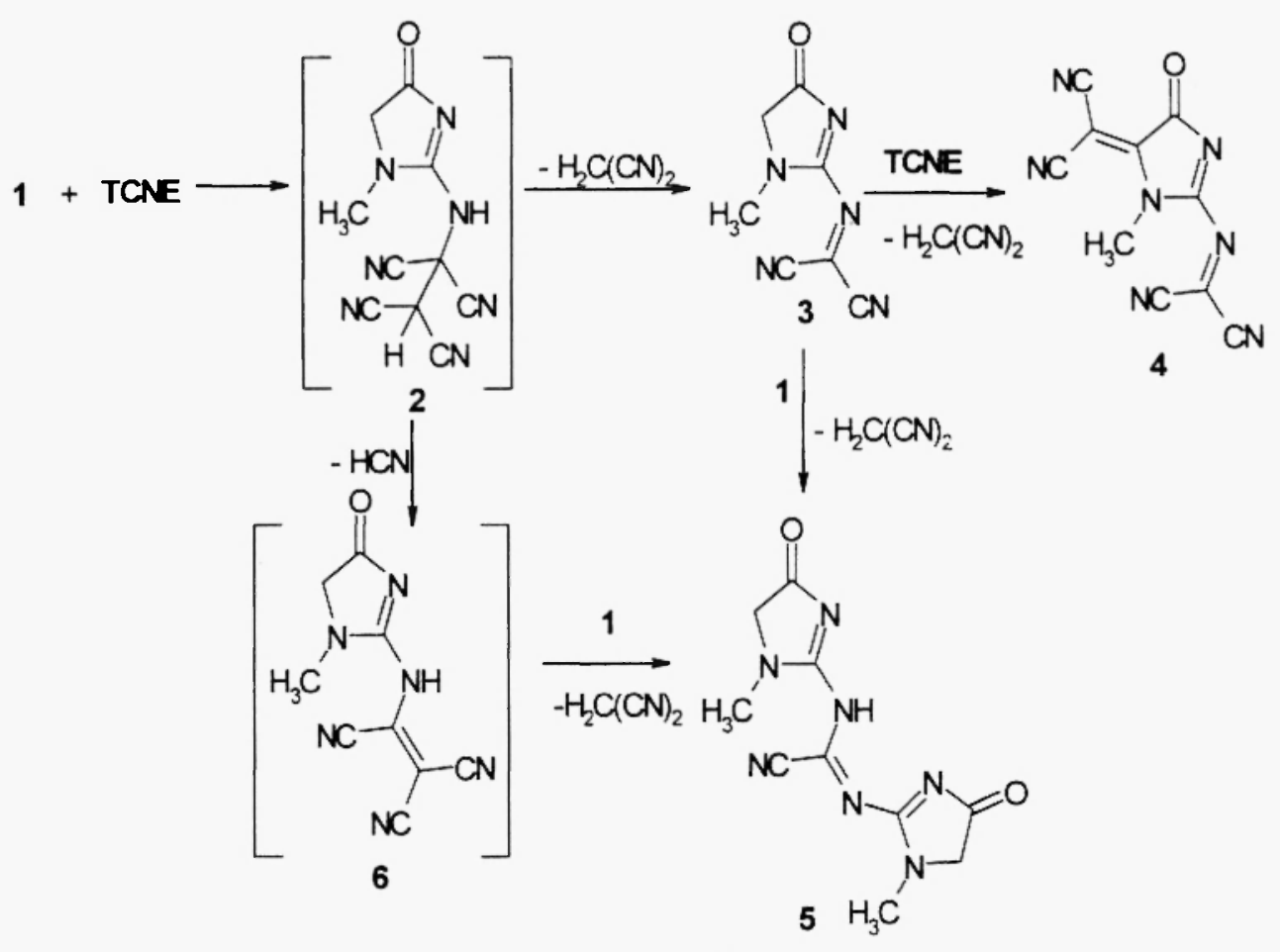<smiles>[Y4][CH-][OH+]</smiles>

\section{Scheme 1}

$110.6 \mathrm{ppm}$. respectively. Correct elemental analysis and mass spectrum further supported the identity of compound 7. which were compatible with the assigned structure.

Since. the reactions occurring when 1 reacted with TCNE require a multitude of steps and are by necessity very complex. moderate yields as found (based throughout on the amount of starting materials used) are acceptable. this needs to be taken into account when determining and evaluating yields. 
In order to study the behavior of creatinine towards benzo-. and naphthoquinone derivatives. creatinine uas subjected to react with 2.3-dicyano-1.4-naphthoquinone (DCNQ) with elimination of one molecule of $\mathrm{HCN}$ and another of water to give 5-cyano-2-dihy.dro-6-hydroxy-1-methyl-naphthoimidazoimidazole (8) (Scheme 2).

The IR spectrum of 8 showed characteristic absorption for hydroxyl group between 3330 and $3400 \mathrm{~cm}^{-1}$.<smiles></smiles><smiles>CC(=O)Oc1c2ccccc2c(O)c2nc3n(c12)C(=O)CN3C(C)C(=O)O</smiles>

$9 \mathrm{HO}$<smiles></smiles><smiles>CCOC(=O)C(C)O</smiles>

\section{Scheme 2}

$2209 \mathrm{~cm}^{-1}(\mathrm{CN})$. as well as $1675 \mathrm{~cm}^{-1}(\mathrm{CO})$. The 'H-NMR spectrum showed two singlets: one at $2.99 \mathrm{ppm}$ $\left(\mathrm{N}-\mathrm{CH}_{2}\right)$ and another at $4.1 \mathrm{ppm}$ (imidazole- $\mathrm{CH}_{2}$ ). in addition to the aromatic protons. The ${ }^{1} \mathrm{C}-\mathrm{NMR}$ spectrum showed some characteristic signals at 168.8 ppm (CO). 155.4 (Ar-C-OH). 163.5 (imidazole- C-2). 121.1. 143.6 due to aromatic carbon atoms attached to imidazole nitrogen.

On the other hand. 2.3-dichloro-1.4-naphthoquinone (DCHNQ) reacted with creatinine with elimination two molecules of $\mathrm{HCl}$ and acetylation of one hydroxyl group of hydroquinone to give 5-acetyl-2-dihydro-10- 
hydroxy-1-methylnaphthoimidazoimidazole (9) (Scheme 2). The IR spectrum of 9 showed characteristic absorption between 1660 and $1700 \mathrm{~cm}^{-1}$ due to creatinine and acetyl

carbonyl groups. The ' $\mathrm{H}-\mathrm{NMR}$ spectrum confirmed the presence of $\left(\mathrm{CH}_{3} \mathrm{CO}\right)$ at $2.15 \mathrm{ppm}$ and $\left(\mathrm{N}_{-} \mathrm{CH}_{3}\right)$ at 2.99 as well as imidazole- $\mathrm{CH}_{2}$ at $4.13 \mathrm{ppm}$. The ${ }^{1:} \mathrm{C}-\mathrm{NMR}$ showed also the following characteristic signals: 58.8 (imidazole- $\left.\mathrm{CH}_{2}\right) .165 .3\left(\mathrm{CH}_{3} \mathrm{COO}\right.$ ). in addition to the signals due to aromatic carbon atoms in their expected values. The structures of $\mathbf{8}$ and $\mathbf{9}$ were established also from the mass spectra. which gave correct molecular ions supported by the elemental analy ses.

In a different manner. creatinine reacted with 2.3-dicyano-5.6-dichloro-1.4-benzoquinone (DDQ) and 2.3.5.6-tetrachloro-1.4-benzoquinone (CHL- $p$ ) to give bisimidazobenzobisimidazole derivatives $\mathbf{1 0}$ and $\mathbf{1 1}$ respectively ria elimination of two molecules of $\mathrm{HCl}$ and another two of $\mathrm{H}_{2} \mathrm{O}$. The elemental analysis of 1.6 dimethyl-3.8-dihydroxy-10.11-dicyanobisimidazo[3.3-h:3.2-h]benzo[1.2-d:4.3-d]bisimidazole (10) showed no evidence for the presence of halogen. Furthermore. the mass spectrum gave strong evidence for the structure of 10. which exhibited a molecular ion at $\mathrm{m} / \mathrm{z} 346(29 \%)$. The ${ }^{1} \mathrm{H}-\mathrm{NMR}$ spectrum showed the presence of two singlets: one at $5.6 \mathrm{ppm}$ due to imidazole- $\mathrm{CH}$ and the other at $2.97\left(\mathrm{~N}-\mathrm{CH}_{3}\right)$. The ${ }^{15} \mathrm{C}-\mathrm{NMR}$ spectrum of 10 showed absorption signals at $\delta 141.8$. 125.7. and 89.9 for imidazole-C-2. C -4 . and $\mathrm{C}-5$ respectively. beside the other carbons. The IR spectrum of 10 showed absorption bands at $3+50-3300(\mathrm{OH})$ and at $2210(\mathrm{CN}) \mathrm{cm}^{-1}$.

1.8-Dimethyl-3.3-dihydroxy-5.12-dichlorobisimidazo[3.2-b:3.2-b]benzo-[1.3-d:4.3-d]bisimid-azole (11) exhibited one absorption band in the IR spectrum around $3430-3300 \mathrm{~cm}^{-1}$ due to hydroxyl groups in addition to the aromatic $\mathrm{C}=\mathrm{C}$ absorption bands. In its ${ }^{1 .} \mathrm{C}$-NMR spectrum. the characteristic resonance signals of the two carbon atoms of chloranil at $\delta=169.9 \mathrm{ppm}^{-2.2}$ is replaced by two signals at 130.2 and $134.7 \mathrm{ppm}$. which are characteristic for aromatic carbon attached to imidazole-N. The elemental analysis and fragmentation pattern of the mass spectrum further confirms the structure of 11 .

In conclusion. the results obtained in this paper have demonstrated that the products resulted from the reaction of 1 with TCNE confirms that the secondary nitrogen atom in position 3 and the imino group in position 2. In addition. the methylene group in position $j$ are considered as the reaction sites. whereas. in case of the reaction of 1 with benzo-. and naphthoquinones. positions 2 and 3 are the active centers. On the basis of structure features of benzo-. and naphthoquinones. they react with 1 in a different manner as TCNE. Consequently. interesting and unexpected novel reaction products were obtained in one step that can not be easily prepared by conventional synthetic methods.

\section{Experimental}

Mps are uncorrected. The IR spectra were recorded on a Nicolet 320 FT. IR and Shimadzu 470. 408 spectrophotometers using potassium bromide pellets. 'H-NMR and ' $\mathrm{C}$-NMR spectra were recorded on a Bruker AM $400(400.1 \mathrm{MHz})$ spectrometer: the chemical shifts were expressed as $\delta(\mathrm{ppm})$ with TMS as internal standard. The mass spectra ( $70 \mathrm{eV}$. electron impact mode) were obtained on a Finnigan MAT 8430 and Jeol JMS 600 spectrometers. The microanalytical unit at Cairo University carried out combustion analyses. Preparative layer chromatography used air-dried $1.0 \mathrm{~mm}$ thick layers of slurry-applied silica gel 
Merck $\mathrm{PF}_{2 s_{1}}$ on $48 \mathrm{~cm}$ wide and $20 \mathrm{~cm}$ high glass plates. Zones were detected by their color or by quenching of indicator fluorescence upon exposure to $254 \mathrm{~nm}$ light.

Staring Materials: Creatinine( 1-methyl-2-amino-1.5-dihydroimidazol-4-one.1) was purchsed from Aldrich. TCNE. DCNQ. DDQ. CHL- $p$ and DCHNQ were prepared and purified as described before. ${ }^{10}$

Reaction of creatinine (I) with TC.VE. - To $1 \mathrm{mmol}(113 \mathrm{mg})$ of creatinine in DMF $(10 \mathrm{ml})$ an equimolar amount of TCNE in $10 \mathrm{ml}$ of DMF $w$ as added with stirring at room temperature. The reaction mixture was stirred further 48 hours. then filtered and the precipitate $u$ as $w$ ashed several times with ethanol to give compound 7. The filtrate was concentrated and the obtained brown residue was dissolved in acetone and separated by preparative layer chromatography using toluene/ethỵl acetate (2:1) as eluent to give numerous zones. three of which were extracted. The fastest migrating one contained I-methylimidazolidin-4-only-2iminomalononitrile (3): the second zone. which was characterized by its blue color. contained compound (4). The material confined to the start was rechromatographed using toluene/ethyl acetate $(1: 1)$ to give compound (5).

1-.1Petm.limidazolidin-t-only-2-iminomalononitrile (3): $(26 \mathrm{mg} .15 \%) \mathrm{mp} 296-98{ }^{\circ} \mathrm{C}$ : buff crystals from acetonitrile: $v_{\mathrm{mav}} / \mathrm{cm}^{-1} 2920$ (Ali. CH). $2210(\mathrm{CN}) .1678(\mathrm{CO}): \delta_{\mathrm{H}}\left(\mathrm{DMSO}-\mathrm{d}_{6}\right) 3.95$ (s. $2 \mathrm{H}$. imidazole$\mathrm{CH}_{2}$ ). 2.90 (s. $\left.3 \mathrm{H} . \mathrm{N}-\mathrm{CH}_{3}\right): \delta_{\mathrm{C}}\left(\mathrm{DMSO}_{-} \mathrm{d}_{6}\right) 168.5$ (imidazole-C-4). $164.6\left[\mathrm{C}(\mathrm{CN})_{2}\right] .160 .3$ (imidazole-C-2). 118.2 (CN). 61.4 (imidazole-C-5). $30.3\left(\mathrm{CH}_{5}\right): \mathrm{m} / \mathrm{z}(\%) 175$ (M-100). 149 (44). 147 (18). 119 (23): (Found: C. 47.83: H. 2.93: N. 3.91. C- $\mathrm{H}_{5} \mathrm{~N}_{5} \mathrm{O}(175.079)$ requires C. 47.98: H. 2.88: N. 4.00\%):

5-Dicyanomethlene-1-meth limidazolidin-4-only-2-iminomalononitrile (4) $(45 \mathrm{mg}$. 19\%) $\mathrm{mp}$ 314-16: blue crystals from methanol: $v_{\text {max }}^{-} / \mathrm{cm}^{-1} 2210(\mathrm{CN}): \partial_{\mathrm{H}}\left(\mathrm{DMSO}-\mathrm{d}_{6}\right): 2.91$ (s. $\left.3 \mathrm{H} . \mathrm{N}-\mathrm{CH}_{*}\right): \delta_{\mathrm{C}}\left(\mathrm{DMSO}_{6} \mathrm{~d}_{6}\right): 168.4$ (imidazole-C-4). $163.7\left[\mathrm{C}(\mathrm{CN})_{2}\right] .117 .8(\mathrm{CN}) .29 .8\left(\mathrm{CH}_{3}\right): \mathrm{m} / \mathrm{z}(\%) 237\left(\mathrm{M}^{-} .100\right) .221(31) .195(42)$. 77(22). (Found: C. 50.81: H. 1.36: N. 41.29. $\mathrm{C}_{10} \mathrm{H}_{3} \mathrm{~N}-\mathrm{O}(237.080)$ requires C. 50.62: H. 1.28: N. 41.36\%). 2-Iminobis/ I'-methyl-4 -oxo-2'-dihvdrosimidazoly/cyanoazomethine (5) $(57 \mathrm{mg} .22 \%) \mathrm{mp} 331-33^{\circ} \mathrm{C}$ : brown crystals from methanol: $v_{\text {max }} / \mathrm{cm}^{-1} 2980$ (Ali-CH). $2210\left(\mathrm{CN}\right.$ ). $1670(\mathrm{CO}): \delta_{\mathrm{H}}\left(\mathrm{DMSO}-\mathrm{d}_{6}\right.$ ): 2.94 (s. $6 \mathrm{H} .2 \mathrm{~N}$ $\mathrm{CH}_{5}$ ). 3.99 (s. 4H. 2-imidazole-CH$-\mathrm{CH}_{2}$ ). 8.05 (br.lH. NH. D 20 ): $\delta_{\tau}$ (DMSO-d $\mathrm{d}_{6}$ ): 168.6 (imidazole-C-4).163.7

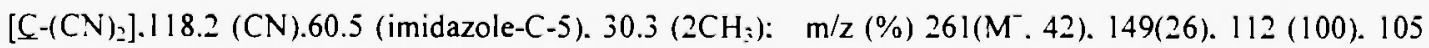
(21). (Found: C.46.08: H. 4.18: N. 37.42. $\mathrm{C}_{10} \mathrm{H}_{11} \mathrm{~N}-\mathrm{O}_{2}(261.143$ ) requires C. 45.96: H. 4.25: N. $37.55 \%$ ). Furo[2.3-b:4.5-d]bis(l-methylimidazolvl)-2-iminomalononitrile (7): (125 mg. $38 \%) \mathrm{mp} 342-44{ }^{\circ} \mathrm{C}$ : brown crystals from DMF: $v_{\max }^{-} / \mathrm{cm}^{-1} 2980$ (Ali-CH). $2210(\mathrm{CN}): \delta_{\mathrm{H}}\left(\mathrm{DMSO}_{\mathrm{f}}\right): 2.95\left(\mathrm{~s} .6 \mathrm{H} .2 \mathrm{NCH}_{\xi}\right): \delta_{\mathrm{C}}$ $\left(\right.$ DMSO-d $\left._{h}\right): 163.5\left[\mathrm{C}-(\mathrm{CN})_{2}\right] .143 .2$ (imidazole-C-4). $118.1(\mathrm{CN}) .110 .6$ (imidazole-C-5). $30\left(\mathrm{CH}_{3}\right): \mathrm{m} / 2(\%)$ 330 (M-22). 294 (17). 277(11). 235 (19). 167(64). 149 (53). 105 (100): (Found:C.51.06: H. 1.0́9: N. 42.54. $\mathrm{C}_{14} \mathrm{H}_{6} \mathrm{~N}_{10} \mathrm{O}(330.128)$ requires C. 50.89: H. 1.83: N.42.43\%).

Reaction of creatinine (I) with DCNQ - A solution of DCNQ (208 mg. $1.0 \mathrm{mmol})$ in $10 \mathrm{ml}$ DMF was added dropwise to a solution of creatinine $1(113 \mathrm{mg} .1 .0 \mathrm{mmol})$ in $10 \mathrm{ml}$ of DMF at room temperature. The reaction mixture becomes deeply blue and later turns into green color. It was left standing for $\mathbf{4 8}$ hours. then concentrated and the residue was purified by plc using toluene/ethyl acetate $(1: 1)$ to give product (8).

5-Cyano-2-dihvdro-6-hvdroxy-1-methylnaphthoimidazoimidasole (8): $(225 \mathrm{mg} .81 \%) \mathrm{mp} 252-54{ }^{\circ} \mathrm{C}$ : green crystals from methanol: $v_{\text {max }}^{-} / \mathrm{cm}^{-1} 3400-3330(\mathrm{OH}) .2209(\mathrm{CN}) .1675(\mathrm{CO}): \delta_{\mathrm{H}}\left(\mathrm{DMSO}-\mathrm{d}_{6}\right) 7.5-8.2(\mathrm{~m} .4 \mathrm{H}$. 
Ar-H). 4.1 (s. $2 \mathrm{H}$. imidazole- $\mathrm{CH}_{2}$ ). 2.99 (s. $3 \mathrm{H} . \mathrm{NCH}$ ): $\delta_{\mathrm{C}}\left(\mathrm{DMSO}-\mathrm{d}_{\hbar}\right.$ ) 168.8 (imidazole-C-4). 163.5 (imidazole-C-2). 155.4 (Ar- $\mathrm{C}-\mathrm{OH}) .143 .6$ (Ar- $\underline{\mathrm{C}}$-imidazole-N). 118.2 .121 .124 .3 .126 .130 .2 .131 (Ar-C)). $116.4(\mathrm{CN}) .58 .9$ (imidazole-C-5). $31.1\left(\mathrm{CH}_{*}\right): \mathrm{m} / \mathrm{z}(\%)=278\left(\mathrm{M}^{-} .29\right) .166(80) .148(100) .71(56) .57(61)$ : (Found: C.64.59: H. 3.74: N. 20.21. $\mathrm{C}_{1}: \mathrm{H}_{10} \mathrm{~N}_{4} \mathrm{O}_{2}$ (278.12) requires C. 64.73: H. 3.62: N. 20.14\%).

Reaction of creatinine (l) with DCHNO A solution of DCHNQ (227 mg. $1.0 \mathrm{mmol}$ ) in glacial acetic acid ( 15 $\mathrm{ml})$ was added in small portions to creatinine $(113 \mathrm{mg} .1 \mathrm{mmol})$ in glacial acetic acid $(10 \mathrm{ml})$ with constant shaking. The mixture was refluxed for 4 hours and left aside overnight. A crude reddish brown solid product was obtained. It was filtered. washed well with water and then recrystallized from DMF/ethanol to give compound (9).

5-Acet!-2-dihydro-10-hydrory-1-meth l-3-oronaphthoimidazoimidazole (9): (230 mg. $74 \%) \mathrm{mp} 283-85^{\circ} \mathrm{C}$ : reddish-brown crystals from DMF/ethanol: $v_{\mathrm{mav}}^{-} / \mathrm{cm}^{-1} 3400-3300(\mathrm{OH}) . \quad 1660-1700(\mathrm{CO}): \delta_{\mathrm{H}}\left(\mathrm{DMSO}-\mathrm{d}_{\mathrm{h}}\right): \delta$ 7.44-8. 18 (m. 4H. Ar-H). 4.13(s. 2H. imidazole-CH. $\mathrm{CH}_{2}$ ). 2.99(s. 3H. NCHs): $\delta_{C}\left(\mathrm{DMSO}_{\mathrm{f}}\right.$ ): 168.8 (imidazoleC-41. 165.3 (acetyl carbonyl carbon). 144.6 (Ar-C-OH). 133.4 (Ar-C-N). 128. 127.1. 123.4 121.2. 120.4. 119.2 (Ar-C)). 58.8 (imidazole-C-5). $30.4\left(\mathrm{CH}_{\mathrm{s}}\right): \mathrm{m} / \mathrm{z}$ (\%) $311\left(\mathrm{M}^{-}, 36\right) .279$ (32). 192(100). 163(94). 135(66). 99 (62): (Found: C. 61.59: H. 4.33: N. 13.58. $\mathrm{C}_{16} \mathrm{H}_{1}: \mathrm{N}_{5} \mathrm{O}_{4}(311.136)$ requires C. 61.71: H. 4.21: N. $13.51 \%)$.

\section{Reaction of creatinine (I) with $D D Q$ and $C H L-p$}

General procedure: A solution of benzoquinone $(1.0 \mathrm{mmol})$ in glacial acetic acid $(15 \mathrm{ml})$ was added in small portions to creatinine $(1.113 \mathrm{mg} .1 .0 \mathrm{mmol})$ in glacial acetic acid $(10 \mathrm{ml})$ with constant stirring for 5 hours at room temperature. The reaction mixture becomes deeply blue or purple and later turns into brown or pale green color. It was left standing for 96 hours at room temperature. A crude solid product was obtained. It was filtered. washed with water and then recrystallized from an appropriate solvent to give the products $\mathbf{1 0}$ and 11.

1.6-Dimethyl-3.8-dihydroxv-10.11-dicvanobisimidazo[3.2-b-3.2-b ]-benzo[1.2-d:-1.3-d] ]bisimid-azole (10): (235 mg. 68\%) mp $327-29^{\circ} \mathrm{C}$ : brown crystals from DMF: $v^{-}{ }_{\max } / \mathrm{cm}^{-1} 3450-3300 \mathrm{~cm}^{-1}(\mathrm{OH}) .2210(\mathrm{CN}): \delta_{\mathrm{H}}$ $\left(\right.$ DMSO-d $\left._{6}\right) \quad 5.6$ (s. 2H. imidazole-CH). 2.97(s. 6H. NCHs): $\delta_{C}\left(\right.$ DMSO-d $\left._{6}\right)$ 140.3.141.8 (Ar- $\mathrm{C}=\mathrm{N}-$ imidazole). 126.4 (Ar-C - N- imidazole). 125.7 (imidazole-C-4). $116.8(\mathrm{CN}) .100 .8 .104 .6$ (Ar- $\Omega_{-}-\mathrm{CN}$ ). 89.9 (imidazole-C-5). $31.3\left(\mathrm{CH}_{3}\right): \mathrm{m} / \mathrm{z}(\%)$ 346(M. 29). 320 (18). 294 (12). 264 (20). 230 (32).111(52). $57(100)$ : (Found: C. 55.58: H. 2.83: N. 32.46. $\mathrm{C}_{16} \mathrm{H}_{10} \mathrm{~N}_{8} \mathrm{O}_{2}(346.147)$ requires C. 55.47: H. 2.91: N. 32.37\%). 1.8-Dimerhvl-3.10-dihvdrony-5.12-dichlorobisimida=o[3.2-b.3.2-b ]-ben=o-[1.3-d:-.3-d]bisimid-azole (11): (281 mg. $77 \%$ ) mp $293-95^{\circ} \mathrm{C}$ : pale yellow crystals from DMF: $v_{\text {max }}^{-} / \mathrm{cm}^{-1} 3430-3300(\mathrm{OH}), 1610$ (Ar-C=C):

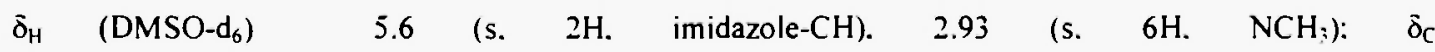
(DMSO- $\mathrm{d}_{6}$ ) 141.4 (imidazole-C-2). 134.7. 130.2 (Ar-C-N-imidazole). 125.4 (imidazole-C-4)). 105.00. 104.1 (Ar-C-Cl). 89.8 (imidazole-C-5). $30.2\left(\mathrm{CH}_{3}\right): \mathrm{m} / \mathrm{z}$ (\%) 370/366 (M.32). 330 (27) . 294 (19). 264 (34). $111(41) .73(100)$ : (Found: C. 45.91: H. 2.84: N. 22.89. Cl. 19.55. $\mathrm{C}_{14} \mathrm{H}_{10} \mathrm{~N}_{6} \mathrm{Cl}_{2} \mathrm{O}_{2}$ (365.038) requires $\mathrm{C}$. 46.03: H. 2.76: N. 23.02: El. 19.42\%). 


\section{Acknowledgement}

The authors are indebted to Alexander von Humboldt Foundation for donation of the Shimadzu 408 IR spectrophotometer.

\section{References}

(1) D. Villemin and B. Martin. Sinth. Commun.1995. 25. 3135 (1995).

(2) S. M. Ramsh. N. G. Zheltonog and E. S. Khrabrova. Khim. Geterotsikl Soedin. 10 . $1+01$ (1989). C.A. 113. 23762r (1990).

(3) S. M. Ramsh. N. G. Zheltonog. and E. S. Khrabrova. Geterotsikl. Soedin. 6. 767 (1991). C.A. 116. $41421 \vee(1992)$.

(4) E. El-Desoky. S. Aboul-Fetouh. and M. A. Metwally. .J. Chem. Technol. Biotechnol. 67. 153 (1996)

(5) K. Skog. M. G. Knize. J. S. Felton. and M. Jaegerstad. Mutat. Res. 268. 191 (1992). C.A. 117. $190480 \mathrm{~m}$ (1992).

(6) B. Mali. and P. C. Nicholas. Biochem. Soc. Trans., 15. 1160 (1987).

(7) B. Mali. and P. C. Nicholas. Biochem. Soc. Trans.. 15. 1162. 1163 (1987).

(8) K. Nakamura. C. Ohira. H. Yamamoto. W. Pfleiderer. and K. lenaga. Bull. Chem. Soc. Jpn.. 63. 1540 (1990).

(9) J. J. Roberts and J. B. Walker. J. Biol. Chem. 260. 13502 (1985). C. A. 103. 193663v (1985).

(10) M. Kawase. A. K. Sinhababu. E. M. McGhee. T. Milby and R. T. Borchardt. J. Med. Chem.. 33. 2204 (1990).

(11) A. R. Butler and C. Glideww II. J. Chem. Soc.. Perkm Trans 2. 1465 (1985).

(12) A. V. Arakali. J. McCloskey. R. Parthasarathy. J. L. Alderf. G. B. Chheda and T. Srikrishman. Nucleosides Nucleorides. 16. 2193 (1997).

(13) R. P. Srivastava and S. Sharma. Indian j. Chem.. 29B. 142 (1990).

(14) A. M. Kadry. E. H. Abd El-Al and H. A. Abdel-Fattah. Bull. Fac. Pharm. (Cairo Cnin.). 29. 21 (1991).

(15) A. A. Hassan. N. K. Mohamed. Y. R. Ibrahim. K. U. Sadek and A. E. Mourad. Bull. Chem. Soc. Jpn. 66, 2612 (1993).

(16) A. A. Hassan. N. K. Mohamed. B. A. Ali. and A. E. Mourad. Tetrahedron. 50 (33). 9997 (1994).

(17) A. A. Hassan. N. K. Mohamed. E. H. El-Tamany. B. A. Ali. and A. E. Mourad. Monarsh. Chem. 126.653 (1995).

(18) A. A. Hassan. A. A. Aly. N. K. Mohamed and A. E. Mourad. J. Chem. Research (S), 208 (1996).

(19) A. A. Hassan. N. K. Mohamed A. A. Aly and A. E. Mourad. Bull. Soc. Chim. Belg. . 159 (1996).

(20) N. K. Mohamed. A. A. Aly. A. A. Hassan. A. E. Mourad and H. Hopf. J. Prakı. Chem.. 338. 754 (1996).

(21) A. A. Hassan. D. Döpp and G. Henkel. J. Heterocvclic Chem. 35.121 (1998).

(22) D. Döpp. M. A. Gomaa and G. Henkel. J. Heterocvclic Chem.. 32. 603 (1995).

(23) H. O. Kalinowski. S. Berger and S. Brun ".' $C-N M R$ Spectroscopl ${ }^{*}$. George Thieme Verlag. Stuttgart. 1984

\section{Received on November 11, 2001}

